\title{
The Interface of Oxytocin-Labeled Cells and Serotonin Transporter-Containing Fibers in the Primate Hypothalamus: A Substrate for SSRIs Therapeutic Effects?
}

\author{
Ana BF Emiliano', Thomaz Cruz', Valerie Pannoni ${ }^{2}$ and Julie L Fudge ${ }^{*, 2,3}$ \\ 'Department of Medicine, Universidade Federal da Bahia, Bahia, Brazil; ${ }^{2}$ Department of Psychiatry, University of Rochester Medical Center, \\ Rochester, NY, USA; ${ }^{3}$ Department of Neurobiology and Anatomy, University of Rochester Medical Center, Rochester, NY, USA
}

\begin{abstract}
Oxytocin (OT) is a neuropeptide synthesized in the paraventricular (PVN) and supraoptic nuclei (SON) in the hypothalamus. Although OT is more commonly known for its role in the milk-ejection reflex, in recent years research has indicated that OT participates in the expression of social behavior, memory processing, modulation of fear, and stress responses. The demonstration that OT influences affiliative behaviors, such as parental care and reproduction, and decreases anxiety has lead to speculations that it may have a role in mood disorders. Evidence from pharmacologic studies, pointing out the modulation of the OT system by serotonin, has argued in favor of OT as a mediator of serotonin reuptake inhibitors (SSRIs) antidepressant properties. In the present study, we investigated the distribution and overlap of OT-labeled cells and serotonin transporter (5-HTT) immunoreactive (IR) fibers in the Macaque hypothalamus, utilizing immunocytochemical and double-immunofluorescent techniques. Consistent with previous reports, the distribution of OT-labeled cells in the hypothalamus is confined to the PVN and SON. In these nuclei, we demonstrate that the distribution of 5-HTT-labeled fibers follows the distribution of OT-labeled cells. Overlap of OT-labeled neurons and 5-HTT-IR fibers occurs in the parvicellular, magnocellular, dorsal, and posterior subdivisions of the PVN. In the SON, 5-HTT-labeled fibers and OTlabeled cells overlap in the ventromedial subdivision and in the 'capsular' part of the dorsolateral SON. These findings provide neuroanatomic support for the idea that SSRIs' therapeutic effects on social affiliation and anxiety may be mediated in part through components of the OT system.
\end{abstract}

Neuropsychopharmacology (2007) 32, 977-988. doi:I0.I038/sj.npp. I 30 I206; published online II October 2006

Keywords: paraventricular nucleus; supraoptic nucleus; affiliation; depression; stress; suckling

\section{INTRODUCTION}

In the past three decades, oxytocin (OT) has been raised to the status of a neurotransmitter (Buijs and Van Heerikhuize, 1982; Sofroniew et al, 1981; Vandesande and Dierickx, 1975; see review by Muhlethaler et al (1985)). Beyond participating in the milk ejection reflex and parturition, this neuropeptide is now recognized for its influence on affiliative behaviors and the formation of social bonds (Insel, 1992), memory processing (see review by De Wied (1984)), modulation of stress (Ebner et al, 2005; Windle et al, 2004; Windle et al, 1997), and responses to fear stimuli (Kirsch et al, 2005). OT is a nonapeptide,

*Correspondence: Dr JL Fudge, Departments of Psychiatry, and Neurobiology and Anatomy, Box 603, University of Rochester Medical Center, Rochester, NY 14642, USA, Tel: + I 585273 2028, Fax: + I 585756 5334, E-mail: Julie_fudge@urmc.rochester.edu Received 21 March 2006; revised 7 August 2006; accepted 8 August 2006

Online publication: 14 August 2006 at http://www.acnp.org/citations/ Npp08|406060 |83a/default.pdf belonging to the vasopressin-OT family, and is synthesized by neurons in the paraventricular nucleus (PVN) and supraoptic nucleus (SON) of the hypothalamus. These neurosecretory cells send projections to the posterior pituitary, where OT is released into the systemic circulation (Scharrer and Scharrer, 1940; Swanson and Kuypers, 1980). OT-labeled fibers have been identified in various brain regions, including the limbic system and brain stem, indicating direct central effects on specific regions (Caffe et al, 1989; Fliers et al, 1986; Fodor et al, 1992; Sofroniew, 1980).

OT's role in affiliative behaviors suggests it is important in social adaptation. Affiliation encompasses behaviors associated with parental care and reproduction, as well as behaviors that ultimately lead to close proximity of conspecifics, such as grooming. The demonstration of a differential distribution of OT receptors in the monogamous and highly parental prairie vole in comparison to the polygamous and nonsocial montane vole, brought to light the influence of OT on the expression of social behavior (Shapiro and Insel, 1992). In the prairie vole, 
ligand-binding studies show OT receptors in high concentrations in the 'reward circuit' sites, which are absent in the less affiliative montane vole. During the post-partum, when the montane vole displays maternal behaviors towards her offspring, there is a shift in the distribution of OT receptor binding towards the 'reward circuit' pattern seen in the prairie vole (Insel, 1992). This suggests that OT shapes rewarding aspects of affiliative behaviors necessary for survival in some species.

In addition to influencing reward circuits, OT also modulates the stress response. OT deficient animals display increased anxiety behaviors (Amico et al, 2004; Mantella et al, 2003), and release more corticosterone after a stressor (Amico et al, 2004). At the same time, OT administration reduces anxiety behaviors in typical stress paradigms, decreasing corticosterone release (Bale et al, 2001; Neumann et al, 2000; Windle et al, 2004, 1997).

A decline in social and 'affiliative' behaviors, along with altered stress responses, characterizes major depression (Holsboer et al, 1995; Nelson and Charney, 1981). Although OT is associated with enhanced social behavior and adaptation to stress, the serotonin and other monoamine systems are typically associated with amelioration of social isolation and anxiety found in mood disorders (see review by Castren (2005)). For example, these symptoms resolve after chronic treatment with serotonin reuptake inhibitors (SSRIs), which enhance serotonin transmission by blocking the serotonin transporter (5-HTT). 5-HTT is the molecule responsible for clearing serotonin released in the synapse (Blakely et al, 1994) and alterations in its expression have been linked to mood disorders (Arango et al, 2001; Kugaya et al, 2004). The fact that both OT and serotonin can modulate stress and affiliative responses naturally raises the question of how serotonin might influence the OT system, and the specific brain regions in which this occurs.

As a first step in seeing whether serotonin might exert its therapeutic effects via the OT system, we examined the anatomy of these systems in nonhuman primates. In the present study, we investigate the extent to which there is overlap of 5-HTT-immunoreactive (IR) fibers and OT-labeled cells in the primate hypothalamus utilizing immunocytochemical and double immunofluorescent techniques.

\section{METHODS}

One female (MFJ7) Macaque fascicularis and five male Macaque nemestrina (MNJ1, MNJ2, MNJ3, MNJ5, MNJ6) were used in these studies. All experiments were carried out in accordance with the National Institutes of Health guidelines. Experimental design and techniques were aimed at minimizing animal use and suffering, and were reviewed and approved by the University of Rochester Committee on Animal Research. Initial anesthesia was administered by an intramuscular injection of ketamine $(10 \mathrm{mg} / \mathrm{kg})$, and a deep anesthesia was induced by intravenous injection of pentobarbital (initial dose $20 \mathrm{mg} / \mathrm{kg}$ i.v. and maintained as needed). Animals were deeply anesthetized, and killed by perfusion through the heart with saline containing $0.5 \mathrm{ml}$ of heparin sulfate, followed by $4 \%$ paraformaldehyde solution in $0.1 \mathrm{M}$ phosphate buffer ( $\mathrm{pH}$ 7.4). The brains were then removed, and cryoprotected in increasing gradients of sucrose $(10,20$, and $30 \%)$. Serial sections of $50 \mu \mathrm{m}$ were cut on a freezing microtome and transferred into $0.1 \mathrm{M}$ phosphate buffer or cryoprotectant solution.

\section{Immunocytochemistry}

Sections from adjacent compartments were selected for immunostaining with OT (Immunostar, Hudson, WI, 1:10 000, rabbit polyclonal) and 5-HTT (MAB Technologies Inc., Stone Mountain, GA, mouse monoclonal 1:150 000) antibodies, and for cresyl violet staining. One compartment was also selected for 5-HT immunostaining for comparison with 5-HTT IR (Immunostar, Hudson, WI, 1:100,000, rabbit polyclonal). Dilution curves were performed before the actual experiments to determine the optimal concentration of each primary antibody. Control sections in which the primary antibodies were omitted resulted in no IR staining of cells or fibers. Sections were first thoroughly rinsed in $0.1 \mathrm{M}$ phosphate buffer $(\mathrm{pH} 7.2)$ with $0.3 \%$ Triton X-100 (PB-T). Following treatment with endogenous peroxidase inhibitor (EPI), and more $\mathrm{PB}-\mathrm{T}$ rinses, the tissue was preincubated in $10 \%$ normal goat serum (NGS) diluted with PB-T (NGS-PB-T) for $30 \mathrm{~min}$. In the 5-HTT and 5-HT experiments, $1 \%$ bovine serum was added to the NGS to reduce background staining. Tissue was then placed in primary anti-sera to OT, 5-HTT, and 5-HT respectively, and incubated for four nights at $4{ }^{\circ} \mathrm{C}$. Following rinses with $\mathrm{PB}-\mathrm{T}$, the sections were incubated with the appropriate biotinylated secondary antibodies and visualized using the avidin-biotin complex reaction (Vectastatin $\mathrm{ABC}$ kit, Vector Labs, Burlingame, CA). Staining was enhanced by incubating sections for $1-3 \mathrm{~min}$ in $3,3^{\prime}$ diaminobenzidine tetrahydrochloride $(\mathrm{DAB})$ and $0.03 \%$ hydrogen peroxide. Sections were mounted on subbed slides, dehydrated in increasing gradients of alcohol, cleared in xylene and cover slipped. Several immunostained compartments were counterstained with cresyl violet. Following analysis of singlelabeled adjacent sections, additional compartments from one female (MFJ7) and two male (MFJ2 and JFJ5) monkeys were chosen for double labeling of OT and 5-HTT. For double-labeling using $\mathrm{DAB}$, sections were first processed for OT and nickel-intensified to yield a blue-black reaction product in OT-labeled cells. Sections were secondarily processed for 5-HTT without nickel intensification to give a light brown labeling of 5-HTT-positive fibers.

\section{Double-Immunofluorescence-Labeling Protocol}

Dilution curves were first performed in single label immunofluorescence experiments to optimize fluorescent signal and minimize background staining. After treatment with EPI, and incubation in $10 \%$ NGS, selected sections were incubated for four nights in pooled OT (rabbit, 1:10000) and 5-HTT (mouse, 1:75000) antibodies at $4{ }^{\circ} \mathrm{C}$. Then, tissue was thoroughly rinsed in PB-TX, incubated in $10 \%$ NGS-PB-TX for $30 \mathrm{~min}$, and incubated in the dark for four hours in filtered Alexafluor 546 (anti-rabbit IgG antibody) and Alexafluor 488 (anti-mouse IgG antibody) (Molecular Probes Inc., Eugene, OR), to react with the OT and 5-HTT primary antibodies, respectively. Control experiments in which the fluorescent secondary antibodies 
were 'reversed' (eg Alexafluor 546 anti-mouse IgG antibody to 5-HTT primary antibody; Alexafluor 488 anti-rabbit IgG antibody to the OT primary antibody) were also performed to ensure similar patterns of labeling. Tissue was then rinsed for $1 \mathrm{~h}$, mounted on slides, and coverslipped in aqueous medium (Vectashield, Vector Labs).

\section{Analysis}

For DAB-immunoreacted compartments, the distribution of OT-labeled cells in the hypothalamus was hand-charted under bright-field illumination using a drawing tube attached to the microscope ( $\times 10$ objective). Hand-drawn charts were then entered into the computer using the application Canvas 5.0 (ACD Systems, Victoria, British Columbia, Canada) in conjunction with a drawing tablet (Wacom Technology Corp., Vancouver, WA). 5-HTTlabeled fibers were hand-charted under bright and dark field illumination, also using camera lucida techniques ( $\times 10$ objective). Paper charts of labeled fibers and surrounding landmarks, including fiber tracts and blood vessels, were then scanned into the computer using the program Adobe Photoshop 6.0 (300 dpi) (Adobe Inc., San Jose, CA) and imported into the drawing program Canvas 5.0. Finally, the boundaries of the PVN and SON in adjacent Nissl-stained sections were also charted, entered into the computer with the aid of a drawing tablet, and superimposed in transparent layers over charts of OT and 5-HTTlabeled sections. Landmarks such as blood vessels and fiber tracts were used for alignment. 5-HTT and OT-labeled sections counterstained with cresyl violet were examined to confirm these relationships. Sections immunoreacted with 5-HTT and counterstained with cresyl violet were used to assess the relative density of 5-HTT staining across subnuclei. Additional sections double-labeled for OT and serotonin transporter immunoreactivity (5-HTT-IR) using $\mathrm{DAB}$ techniques were examined under high power using oil immersion. After analysis of DAB-labeled sections, additional sections double-labeled for 5-HTT/OT with immunofluorescence antibodies were evaluated using fluorescent microscopy to further confirm the relationships among these markers. Images were captured with an Optronic Microfire color CCD and formatted in Adobe Photoshop. In addition, some sections were examined with confocal laser microscopy using Z-stack analysis $(2 \mu \mathrm{m}$ distance between slices) (Leica Microsystems Inc., Exton, PA).

\section{RESULTS}

\section{Cytoarchitecture}

Since OT-positive cells were mainly confined to the paraventricular and supraoptic nuclei, as previously described (see below), we examined the architecture of these nuclei in cresyl violet stained sections. Admixtures of small and large cells are found throughout the PVN, with relatively subtle differences across subdivisions as has been previously noted (Nauta and Haymaker, 1969; Saper, 1990). The five subnuclei recently described in the human PVN, based on cyto- and chemoarchitectural studies were also appreciated in the monkey (Figure 1). They include the anterior parvicellular subnucleus of the paraventricular

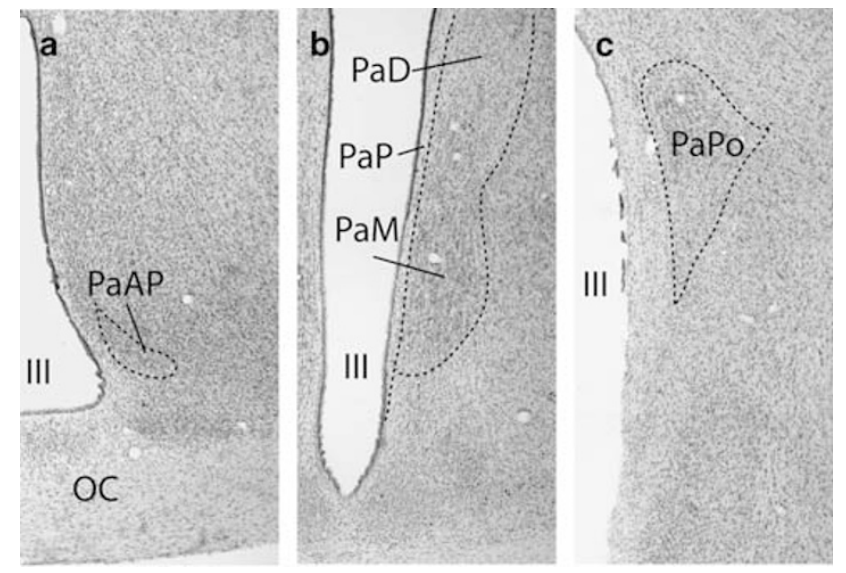

Figure I $(a-c)$ Macroscopic images of coronal sections through the monkey hypothalamus, stained with cresyl violet and arranged in rostralcaudal order. Bar $=50 \mu \mathrm{m}$.

nucleus (PaAP), the parvicellular subnucleus of the paraventricular nucleus $(\mathrm{PaP})$, the magnocellular subnucleus of the paraventricular nucleus $(\mathrm{PaM})$, dorsal subnucleus of the paraventricular nucleus $(\mathrm{PaD})$, and posterior subnucleus of the paraventricular nucleus (PaPo) (Koutcherov et al, 2000). Owing to the similarities with the human PVN, we adopted this nomenclature. At the rostral-most part of the PVN, the small PaAP can be seen in the ventral region of the anterior hypothalamus (Figure 1a). It contains small and mediumsized neurons. Dorsal to it is the rostral tip of the $\mathrm{PaD}$, which occupies a relatively large rostrocaudal expanse of the PVN and is seen in subsequent sections. The PaP, which lies medial to the PaAP and $\mathrm{PaD}$, is also comprised of small cells and forms a thin band along the wall of the third ventricle (III) (Figure 1b). Caudal to the level of the PaAP, the $\mathrm{PaM}$ is seen (Figure 1b). It is characterized by large densely packed dark-staining cells in Nissl stained sections, but also contains small and medium-sized neurons. The $\mathrm{PaD}$ is continuous with the PaM dorsolaterally but is less prominent due to the lower packing density of its large dark-staining cells. Posterior to the descending column of the fornix (f), the wing-like PaPo progressively replaces the $\mathrm{PaD}$, being the only part of the PVN left at the level of the mammillary nuclei (Figure 1c). It contains magnocellular neurons, along with large spindle-shaped cells and small cells.

For the SON, we use nomenclature previously described by Nauta and Haymaker (1969) and Christ (1969). The SON follows the extent of the optic tract and is subdivided into two main regions, the dorsolateral SON (dlSON) and ventromedial SON (vmSON) subdivision (Christ, 1969; LuQui and Fox, 1976) (Figure 2). A third dorsomedial subdivision is seen in humans, however, we did not appreciate this in the monkey, consistent with previous studies (Christ, 1969). The dlSON appears at the level of the optic chiasm and is the only subdivision seen rostrally (Figure 2a, $\mathrm{a}^{\prime}$ ). It contains densely packed magnocellular neurons. At this level, the PVN and SON are bridged by clusters of large multipolar cells, consistent with descriptions of the 'supraoptic accessory nucleus' in humans (Saper, 1990) (Figure 2a', arrow). Further caudal, in the 

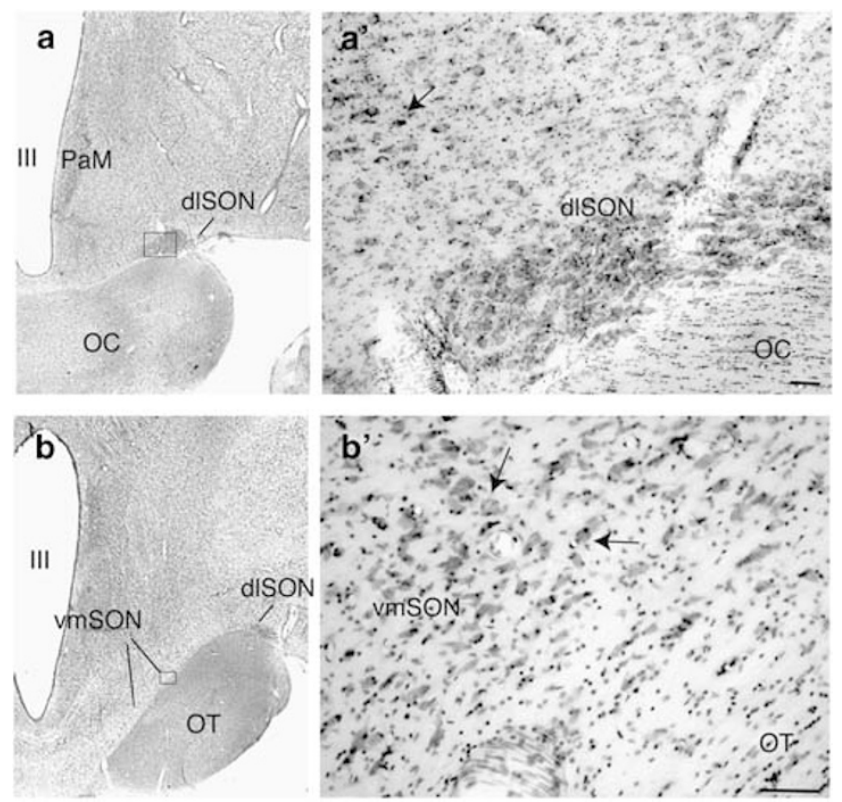

Figure 2 The SON subdivisions at rostrocentral (a, $\left.a^{\prime}\right)$ and caudal $\left(b, b^{\prime}\right)$ levels of the hypothalamus in coronal view. The dISON emerges at the optic chiasm, and is composed of densely packed magnocellular neurons ( $a^{\prime}$ is high power image of boxed area in (a); bar $=50 \mu \mathrm{m}$ ). The supraoptic accessory nucleus is seen dorsomedially, in the region between the SON and PVN (arrow). Posterior to the descussation of the optic chiasm, the SON is composed of the vmSON and dISON. The vmSON is a diffuse collection of neurons embedded in fibers above the optic tract $\left(b^{\prime}\right.$, high power image of boxed area in (b); Bar $=50 \mu \mathrm{m}$ ).

'retrochiasmatic' area, the dlSON moves laterally, and a smaller more diffuse ventromedial subdivision (vmSON) appears (Figure $2 \mathrm{~b}, \mathrm{~b}^{\prime}$ ). The vmSON sends streams of cells dorsolaterally, which join the dlSON.

\section{Distribution of OT-IR Cells in the PVN and SON}

OT-positive neurons are found in the PVN, SON and accessory SON (Figure 3). We classified their relative densities according to the relative number of cells per high-powered field (hpf, $\times 40$ objective) across cases: + sparse $(1-9$ cells/hpf); ++ light $(10-20$ cells/hpf $),+++$ moderate $(21-80$ cells/hpf); ++++ high $(>80$ cells/hpf) (Table 1). There were no appreciable differences in the distributions of labeled cells across animals, nor was there a notable difference in the female animal compared to the males. Oxytocin immunoreactive (OT-IR) cells are mostly large, with darkly stained cytoplasm and prominent proximal dendritic processes (Figure 3e, large arrows), but we also found a number of medium-sized round cells in both the PVN and SON (small arrows).

In general, OT-IR cells form a rostrocaudal continuum through the PVN (Figure 3 and Table 1). There are only occasional OT-positive cells in the PaAP, the most rostral PVN subdivision (Figures $3 \mathrm{a}$ and $4 \mathrm{a}$ ), a light distribution of OT IR cells in the $\mathrm{PaP}$ (Figure $3 \mathrm{a}$ and $\mathrm{b}, 4 \mathrm{~b}$ ), and a moderate density of labeled cells in the rostral PaM (Figures $3 b$ and $c$, 4c). The density of OT-labeled cells increases in the caudal $\mathrm{PaM}$ where it merges with the $\mathrm{PaD}$. The highest density of labeled cells is found in the $\mathrm{PaD}$ (Figure $3 \mathrm{c}, 4 \mathrm{c}$ ). Posterior to the descending column of the fornix, moderate concentrations of OT-labeled cells are identified in the PaPo (Figures $3 \mathrm{~d}$ and $4 \mathrm{e})$.

The SON contains many OT-labeled cells, which tend to cluster medially in the dlSON (Figure $3 \mathrm{a}$ and $\mathrm{b}$ ). In the retrochiasmatic area, where the SON is subdivided, OTlabeled cells are seen in the vmSON, and flow dorsolaterally in a thin stream to encircle the dlSON, forming a 'cap' around the nucleus, avoiding its center (Figures 3d, 4f). Most OT-positive cells in the dlSON are bipolar, whereas relatively smaller, multipolar cells are found in the vmSON.

\section{Distribution of 5-HTT-IR Fibers in the PVN and SON and Overlap with OT + Cells}

5-HTT-containing fibers are widely distributed throughout the primate hypothalamus (Table 1). Overall patterns of 5HTT-IR were similar to those achieved with 5-HT labeling. However, the fine details of fiber labeling were much harder to appreciate with the latter, since $5-\mathrm{HT}$ is also found in extracellular spaces which can obscure fiber labeling. The relative densities of 5 -HTT-labeled fibers are classified based on their distribution throughout the entire hypothalamus (Emiliano et al, in preparation). We classified the densities of fine, varicose 5-HTT-positive fibers based on the degree to which they obscured underlying cellular structures in counterstained sections. Scattered labeled fibers were classified as 'sparse' $(+)$; a fine meshwork of labeled fibers with most underlying cells clearly visible was classified as 'light' $(++)$; a moderate, relatively homogeneous meshwork of labeled fibers, partially obscuring underlying cells was classified as 'moderate' +++ ; and a high, homogeneous density of labeled fibers that almost completely obscured underlying Nissl stained structures was classified as 'heavy' $(++++)$. Based on this classification, concentrations of labeled fibers in the PVN and SON range from sparse to moderate (Table 1 and Figure $5 \mathrm{a}-\mathrm{d})$. There was no obvious difference in 5-HTT distribution between the male animals and the one female. The majority of 5-HTT-containing fibers are thin and finely beaded. Thick, non-beaded fibers coursing through the median eminence and in the median forebrain bundle were interpreted as fibers of passage and were not charted.

Sparse densities of 5-HTT-labeled fibers are found in the $\mathrm{PaAP}$, and there is a light density of labeled fibers in the $\mathrm{PaP}$ (Figure $5 \mathrm{a}$ and $\mathrm{b}$ ). Slightly caudal to this level, moderate densities of labeled fibers occupy the $\mathrm{PaP}$ and the rostral PaM. Moderate densities of labeled fibers occupy the PaM and $\mathrm{PaD}$ (Figure $5 \mathrm{~b}$ and $\mathrm{c}$ ). In caudal-most sections, the PaPo contains a moderate concentration of labeled fibers (Figure 5d). The dlSON displays moderate density of labeled fibers in the dorsal capsular area, with sparse concentrations of 5-HTT-IR fibers in the central core regions (Figure $5 \mathrm{a}$ and $\mathrm{b})$. Moderate concentrations of 5-HTT-IR fibers are found caudally in the vmSON and 'capsular' dlSON (Figure 5c).

Overall, 5-HTT-labeled fibers and OT-IR cells overlap in parallel degrees across PVN and SON subdivisions (Table 1). In general, all PVN subdivisions containing at least moderate concentrations of OT-positive cells- $\mathrm{PaM}, \mathrm{PaD}$, 
a

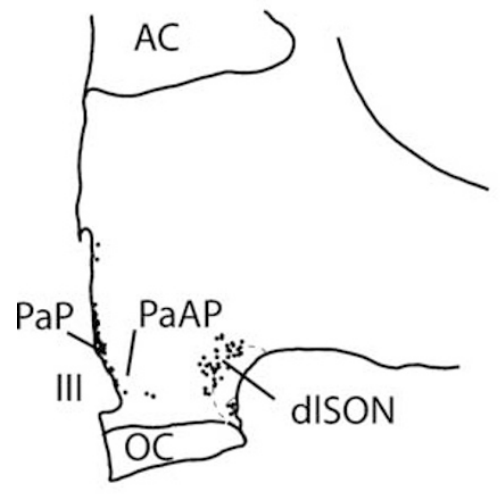

b

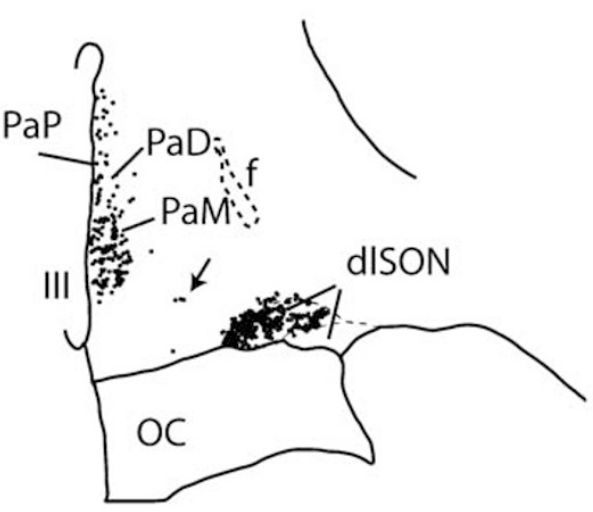

c

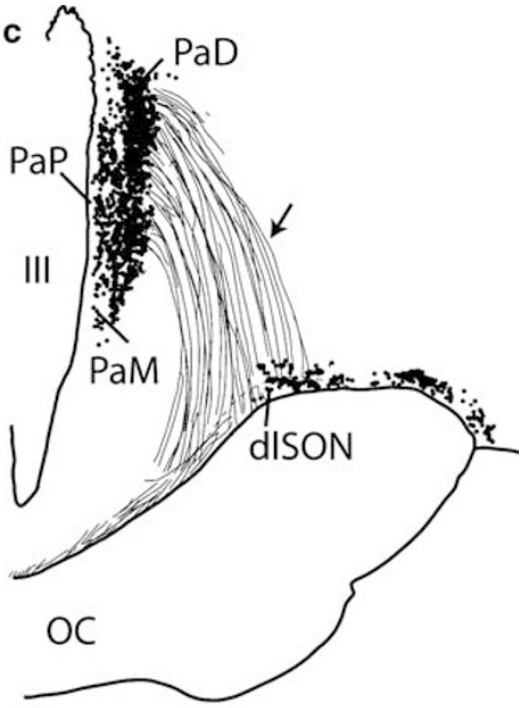

d
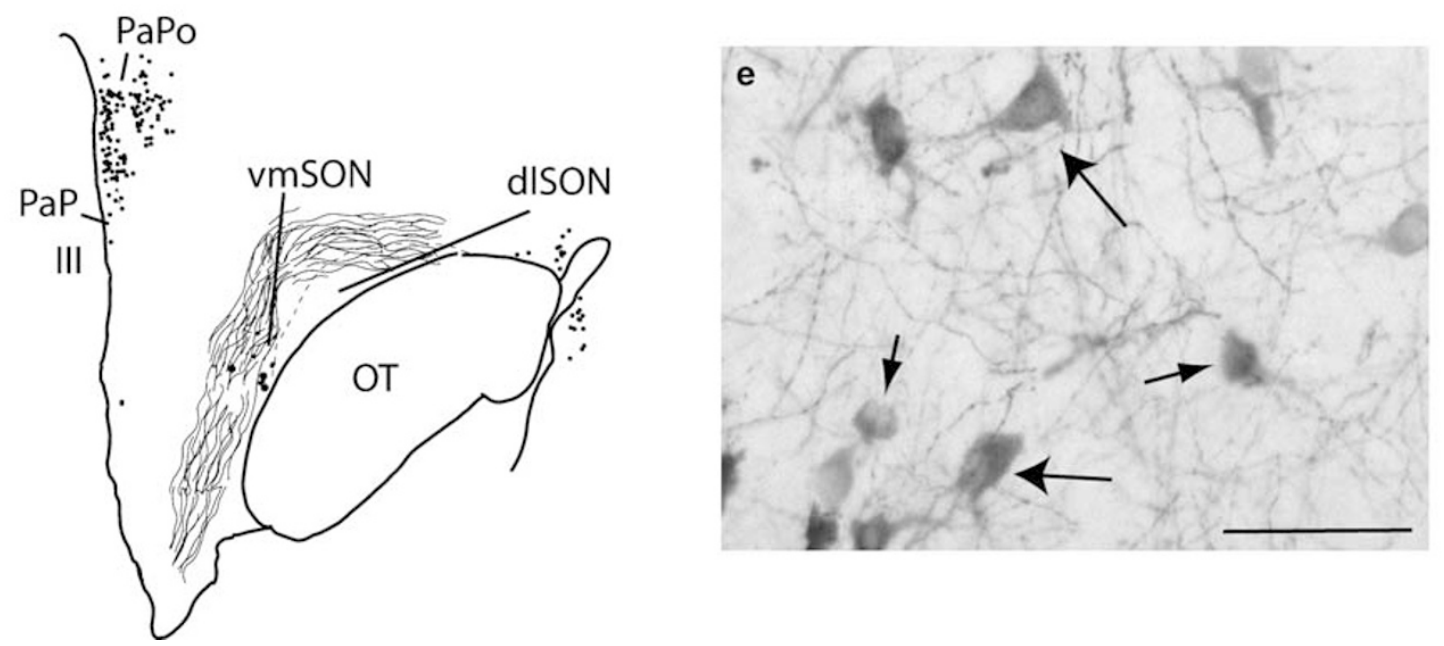

Figure 3 Schematic of the relative distribution of OT-labeled cells in hemi sections through the primate PVN/SON, arranged rostrocaudally. Arrow in (b) depicts the supraoptic accessory nucleus. Arrow in (c) indicates cascades of labeled fibers descending from the PaM and PaD to join OT-labeled fibers from the SON, which then enter the median eminence. I dot = I cell. (e) Photomicrograph of OT-labeled cells in the PVN showing the typical spindle shaped cells (large arrow) and medium-sized, round cells (small arrow). Bar $=50 \mu \mathrm{m}$.

Table I Relative Densities of OT-Labeled Cells and 5-HTTLabeled Fibers in the PVN and SON Subdivisions

\begin{tabular}{lcc}
\hline Hypothalamic nuclei & OT-labeled cells & 5-HTT-labeled fibers \\
\hline $\mathrm{PaAP}$ & + & + \\
$\mathrm{PaP}$ & ++ & ++ \\
$\mathrm{PaM}$ & +++ & +++ \\
$\mathrm{PaD}$ & ++++ & +++ \\
$\mathrm{PaPO}$ & +++ & +++ \\
$\mathrm{dISON}$, capsular & ++++ & +++ \\
$\mathrm{dISON}$, core & + & + \\
vmSON & +++ & +++ \\
\hline
\end{tabular}

The relative densities of OT-positive cells are rated as follows based on approximate numbers of cells per high powered field across cases: + sparse ( I-9 cells/hpf); ++ light (I $0-20$ cells/hpf); +++ moderate ( 2 I-80 cells/hpf); ++++ high ( $>80$ cells/hpf). The relative densities of 5-HTT-labeled fibers are based on their distribution in all hypothalamic nuclei, see text for details: $+=$ sparse; $++=$ light; $+++=$ moderate; $++++=$ high. and $\mathrm{PaPo}$ - also have modest concentrations of 5-HTTlabeled fibers (Figure $6 c$ and $d$ and Figure $7 a-c$ ). These 'magnocellular' subdivisions of the primate PVN thus share similar densities of innervation by 5-HTT-labeled axons. Confocal analysis of these regions revealed 5-HTT-labeled varicose fibers closely apposed OT-IR soma and proximal dendrites (Figure $7 \mathrm{~g}$, see also Figure 6e and f). In contrast, the $\mathrm{PaAP}$ and $\mathrm{PaP}$, which have relatively fewer concentrations of OT-labeled cells, have only a sparse and light distribution, respectively, of 5-HTT-positive fibers (Figure $6 \mathrm{a}$ and b). Similarly, in the SON, subdivisions containing the highest densities of OT-labeled cells (vmSON and capsular dlSON) also receive a moderate concentration of 5-HTT-labeled fibers. Subregions relatively devoid of OT-labeled cells (core of the dlSON) receive only a sparse innervation of 5-HTT-labeled fibers. Under high power confocal microscopy, the close relationship of 5-HTT-labeled boutons and OT-labeled cells in the 'capsular' dlSON is seen, suggesting synaptic contacts (Figure 7). 

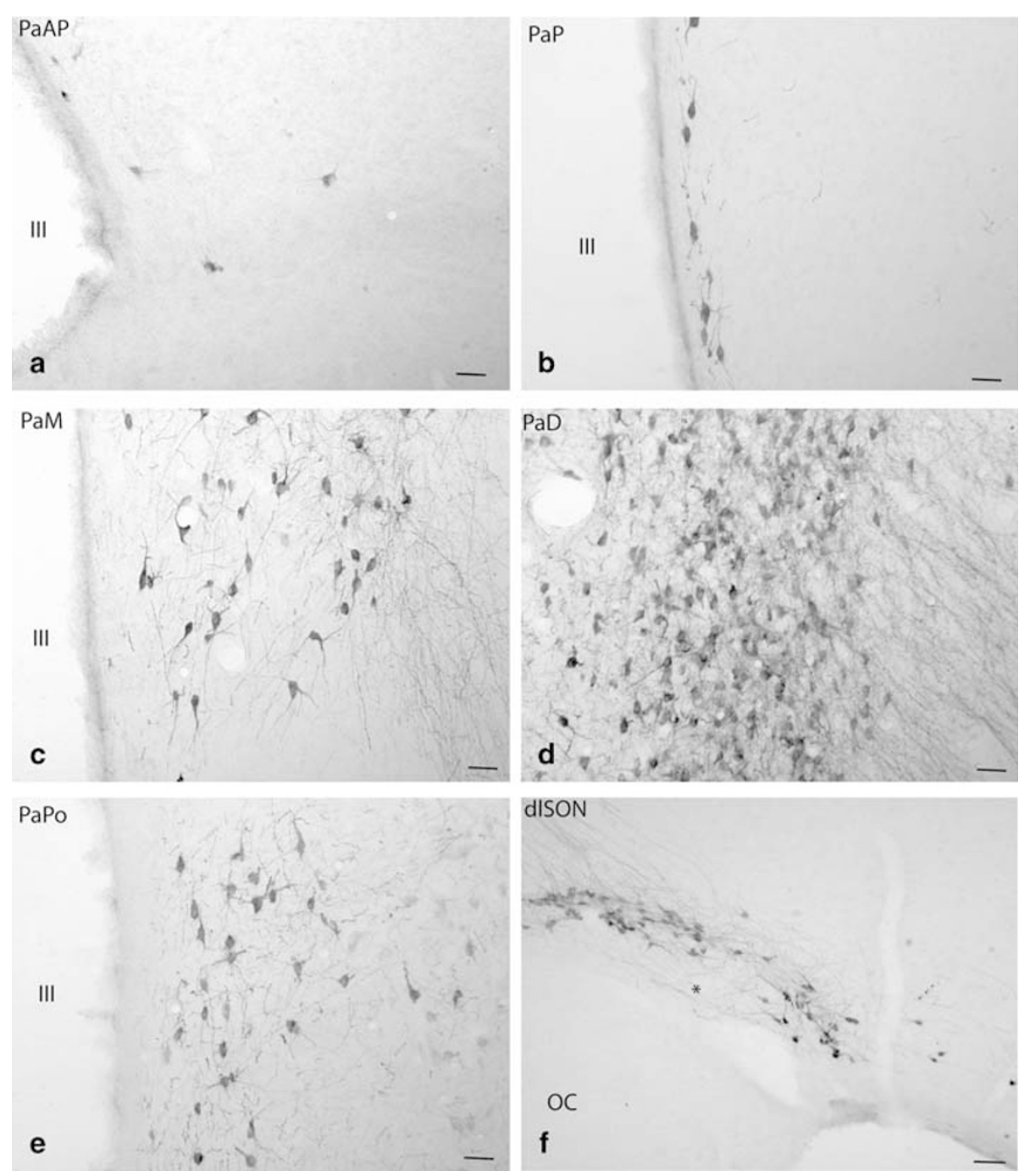

Figure 4 Photomicrographs of OT-labeled cells in the PVN subdivisions (a-e) and the SON ( $\mathrm{f}$. (a) Sparse concentrations OT-IR cells in the PaAP. (b) OT-positive cells in the PaP along the ventricle. (c) The PaM contains moderate densities of OT-labeled cells. (d) Dense concentrations of OT-IR cells in the

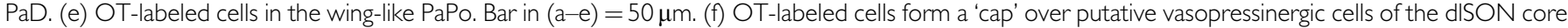
(area without label, asterisk). Bar $=100 \mu \mathrm{m}$.

\section{DISCUSSION}

\section{Summary of Findings and Comparison with Previous Primate Studies}

Cytoarchitecture of the PVN/SON. The organization of the monkey PVN and SON has several similarities to its human counterpart. Consistent with previous studies we found that there are no clear cellular boundaries among PVN subdivisions, with similar cell types crossing several subcompartments (Christ, 1969; Koutcherov et al, 2000; Nauta and Haymaker, 1969; Saper, 1990). Thus, for example, the $\mathrm{PaM}, \mathrm{PaD}$, and $\mathrm{PaPo}$, all contain magnocellular neurons, indicating that the $\mathrm{PaM}$ is not the only 'magnocellular' subdivision. The SON is composed of a large, relatively compact dorsolateral subdivision (dlSON), and a diffuse, slightly caudal ventromedial subregion (vmSON). We found that the monkey lacks the dorsomedial subdivision ('dmSON'), as found in the human (Christ, 1969).
Distribution of OT-containing cells. While the range of nomenclatures for the primate PVN subregions makes comparison of studies difficult, the distribution of OTlabeled cells is consistent across studies (Caffe et al, 1989; Dierickx and Vandesande, 1977; Kawata and Sano, 1982; Koutcherov et al, 2000; Saper, 1990) (present results). The OT-positive cells form a ventral-to-dorsal trajectory along the rostrocaudal extent of the PVN, traversing several subdivisions. The rostral PaAP contains only scattered OTlabeled neurons, while the $\mathrm{PaP}$ contains a light distribution of OT-labeled cells. OT-IR cells are most highly concentrated in caudal 'magnocelluar' subdivisions (the $\mathrm{PaM}, \mathrm{PaD}$, and $\mathrm{PaPo}$ ) with the highest concentration in the $\mathrm{PaD}$. In the SON, the distribution of OT-labeled cells is highest in the vmSON and dorsal 'capsular' subregions of the dISON. These distributions are consistent with results in previous human and nonhuman primate studies (Caffe et al, 1989; Dierickx and Vandesande, 1977; Fliers et al, 1985; Kawata and Sano, 1982). 

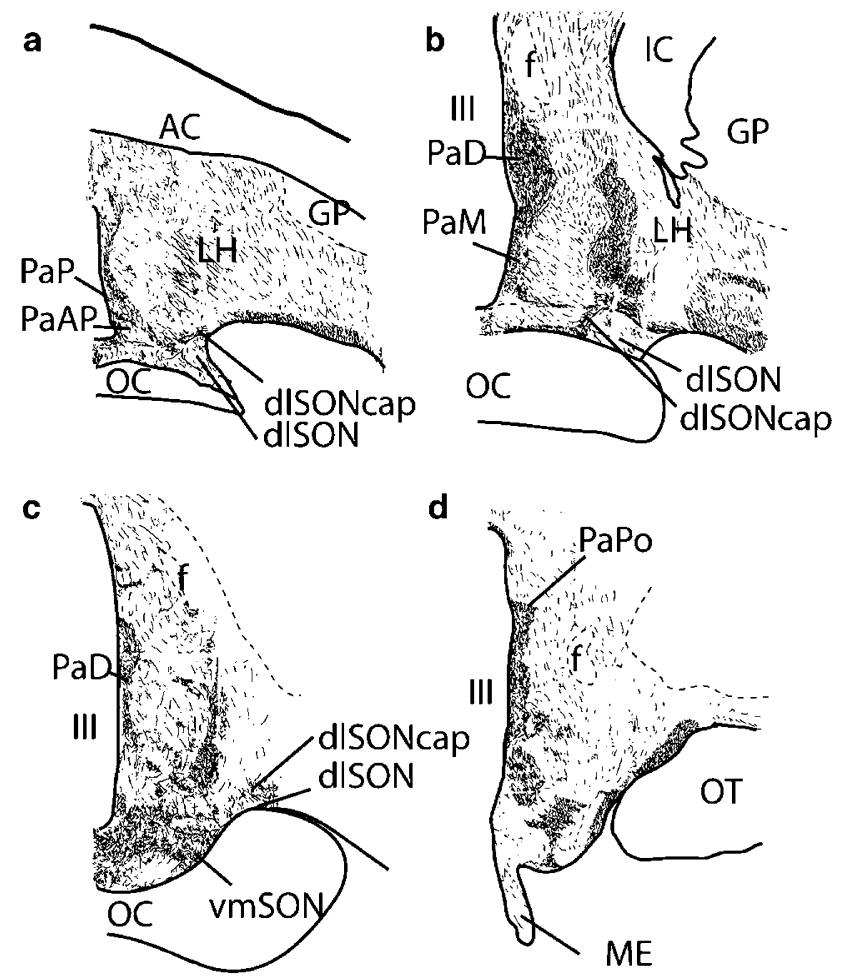

Figure 5 Schematic of the relative distribution of 5-HTT-labeled fibers in hemi-sections through the primate PVN/SON, arranged rostrocaudally.

Distribution of 5-HTT-labeled fibers and overlap with OT-positive cells. The relative densities of 5-HTT-labeled fibers follow the distribution of OT-labeled cells in both the PVN and SON. The PaAP has relatively sparse concentrations of 5-HTT-labeled fibers/OT-labeled cells, the PaP has light concentrations of 5-HTT-labeled fibers/OT-labeled cells, and moderate concentrations of labeled fibers overlap the $\mathrm{PaM}, \mathrm{PaD}$, and $\mathrm{PaPo}$, which contain moderate to heavy concentrations of labeled cells. In the SON, the dorsal 'cap' of the dISON and vmSON, which have heavy and moderate concentrations of OT-labeled cells respectively, are innervated by a moderate concentration of 5-HTT-labeled fibers. In contrast, the ventral dISON (OT-negative) is relatively devoid of labeled fibers.

A single previous study shows a moderate concentration of 5-HT-labeled fibers in the Macaque PVN, with a relatively light concentration of labeled fibers in the dlSON, and a higher concentration of labeled fibers in the vmSON ('nucleus supraopticus difusus') (Kawata and Sano, 1982). While the PVN and SON subdivisions were not defined in that study, the overall pattern of 5-HT-IR is consistent with the present results. Our results are also in agreement with earlier studies using immunofluorescent and biochemical techniques, which report moderate levels of 5-HT labeling the region of the primate PVN (Azmitia and Gannon, 1986; Nobin and Bjorklund, 1973; Schofield and Everitt, 1981).

In rats, immunofluorescence studies indicate a moderately high number of serotonin-containing fibers in the rat PVN (Kent and Sladek, 1978). However, more recent studies utilizing 5-HT immunocytochemistry show relatively low concentrations of 5-HT-labeled fibers in the PVN and SON of that species (Sawchenko et al, 1983; Steinbusch and Nieuwenhuys, 1981) (Emiliano, unpublished observations). However, a preferential input of serotonergic fibers to oxytocinergic regions has been noted, similar to the current findings (Sawchenko et al, 1983).

5-HTT/OT overlap as an anatomic substrate for stimulation of OT: Despite an apparent paucity of 5-HTIR fibers in the rat PVN and SON, numerous pharmacologic studies support this connection. Moreover, the raphe projects to both nuclei (Sawchenko et al, 1983; Tribollet and Dreifuss, 1981). Serotonin receptor stimulation in the PVN causes the release of OT in male and female animals (Bagdy, 1996; Jorgensen et al, 2003b; Moos and Richard, 1983; Saydoff et al, 1991; Van de Kar et al, 1995). Administration of the serotonin-releasing agent D-fenfluramine, results in c-fos expression in OT-containing neurons of both the PVN and SON, indicating that serotonergic transmission activates OT neurons in both those nuclei (Javed et al, 1999). Furthermore, serotonin agonists increase OT mRNA expression in the PVN and SON, suggesting a long lasting effect on OT levels (Jorgensen et al, 2003a). In the present study, the anatomic overlap of 5-HTT-labeled fibers and OT-containing cells in the PVN and SON suggests that serotonin can directly influence the OT system in the primate. While there are few pharmacologic or behavioral studies in monkeys or humans, a recent study shows that OT release is stimulated by fenfluramine administration in healthy men (Lee et al, 2003). An indirect piece of evidence for 5-HT-OT interactions in humans is the well-known prolactin surge associated with fenfluramine challenge (Coccaro et al, 1997; Siever et al, 1984). OT-containing neurons are among the possible mediators of this phenomenon, since OT is a potent prolactin releasing factor (see review by Emiliano and Fudge (2004)).

Mother-infant behaviors as a model of 5-HT/OT interaction: Maternal nursing behavior is one of the few behavioral models of 5-HTT-OT interactions and provides clues on how these connections may promote affiliation and decrease stress. Stimulation of sensory afferents in the nipple are transmitted through the dorsal root ganglia and dorsal horns to the lateral funiculus and the brain stem, activating serotonin cells in the raphe nuclei (Bodnar et al, 2002; Dubois-Dauphin et al, 1985a, b; Fukuoka et al, 1984; Tasker et al, 1986; Tribollet and Dreifuss, 1981). Serotonergic fibers stimulate OT cells in the PVN, which in turn promote prolactin release (Moos and Richard, 1983), based on lesioning and pharmacologic studies (Bodnar et al, 2002; Saydoff et al, 1991). While the release of OT in the systemic circulation causes the 'let-down' of milk, stimulation of central OT may reduce anxiety and stimulate reward circuits. Decreased HPA-axis responsiveness to stress has been demonstrated in both lactating animals and humans. For example, cortisol levels are reduced in breast-feeding women in paradigms of social and running stress (Altemus et al, 1995; Heinrichs et al, 2001). This decreased responsiveness to stress has been attributed to OT, as well as to prolactin and other hormones (Carter and Altemus, 1997; Lightman et al, 1993) and may represent an adaptive mechanism to ensure that this important affiliative behavior 

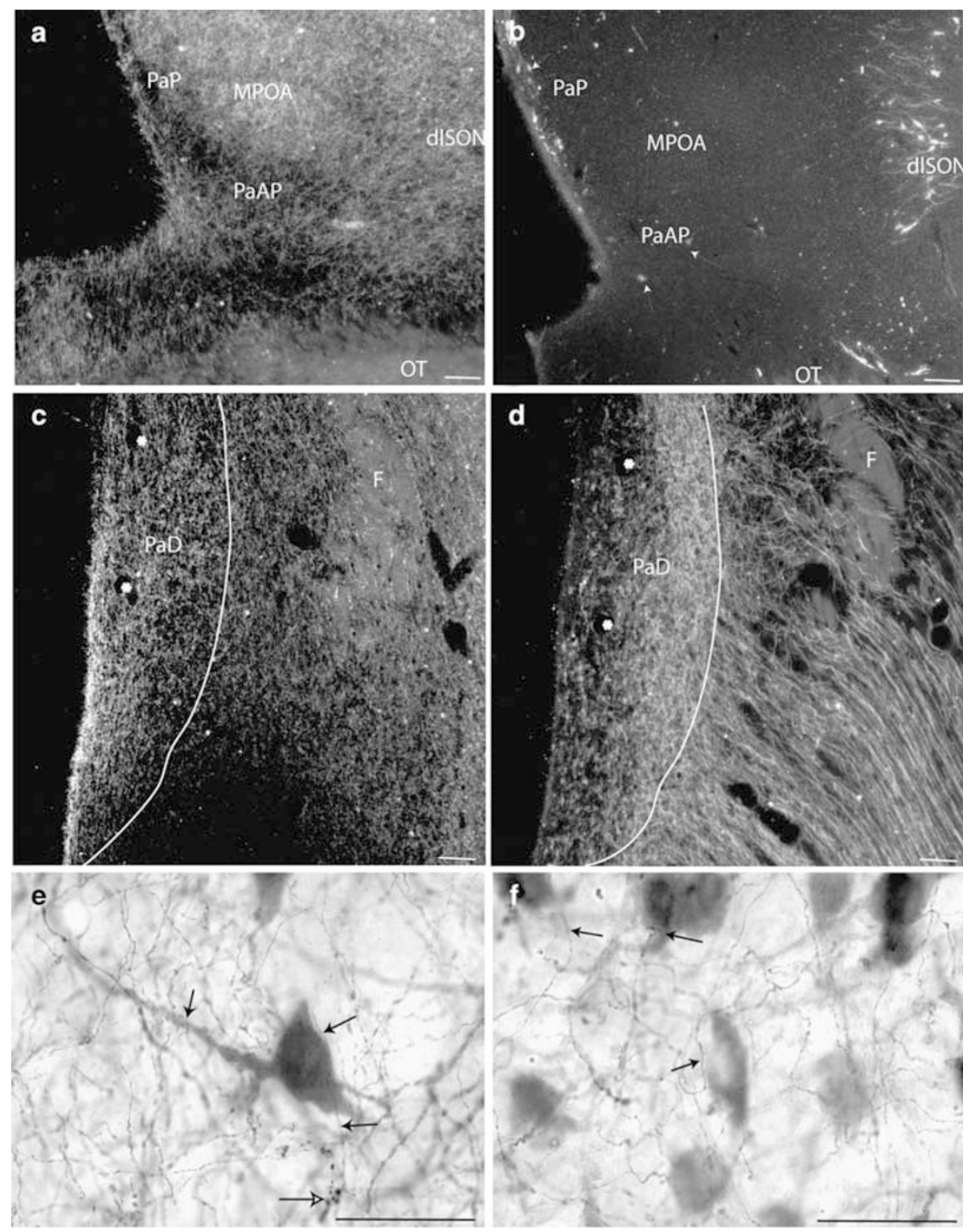

Figure 6 Immunofluorescent labeling in adjacent sections. (a, b) 5-HTT-IR (a) and OT-IR (b) in the PaAP. The PaAP contains minimal concentrations of 5-HTT-IR fibers and scant OT-positive cells. Bar $=50 \mu \mathrm{m}$. (c, d) 5-HTT-IR (c) and OT-IR (d) in the PaM and PaD. OT-labeled cells in these subdivisions are moderate to dense, while 5-HTT-IR fibers are of a moderate concentration (asterisks mark blood vessels). Bar $=100 \mu \mathrm{m}$. (e, f) Double-labeled sections in high power view showing fine varicose 5-HTT-labeled fibers in the PaD in close proximity to OT-positive cells. Black arrows indicate thin 5-HTT-labeled fibers, which can be distinguished from thick beaded OT-containing processes (open arrow). Bar $=50 \mu \mathrm{m}$.

will remain protected from disruptions. Exogenous OT administration to non-nursing human volunteers also decreases basal and stimulated ACTH and cortisol plasma levels (Chiodera and Coiro, 1987; Coiro et al, 1988; Legros et al, 1982).

While attenuating the stress response, OT also activates reward circuits. Nursing rats activate 'reward' regions of the brain in response to pup contact, in contrast to virgin rats. Moreover, nursing dams prefer pup contact to classic drug reward (Ferris et al, 2005). In normal non-nursing animals, exogenous OT administration activates similar reward sites, suggesting that $\mathrm{OT}$ is an important chemical mediator of the rewarding effects of nursing (Febo and Ferris, 2005). Taken together, these studies show that OT release through the serotonin-mediated suckling mechanism is a potent acti- vator of reward circuits as well as an inhibitor of HPA-axismediated stress responses. To the extent that serotonin activates central OT release, it indirectly influences the reward properties of this affiliative behavior and decreases the stress response.

Functional implications. A core symptom of depression is diminished pleasure and interest (Naranjo et al, 2001; Nelson and Charney, 1981), which is effectively treated by serotonin enhancing drugs. It is possible that the efficacy of SSRIs in restoring interest in social interactions is due, in part, to their actions on the reward circuit via the OT system (Insel, 2003; Swaab et al, 2000; Uvnas-Moberg et al, 1999). SSRIs also attenuate anxiety and depressive behavior, an effect that may also be partly mediated by downstream OT 

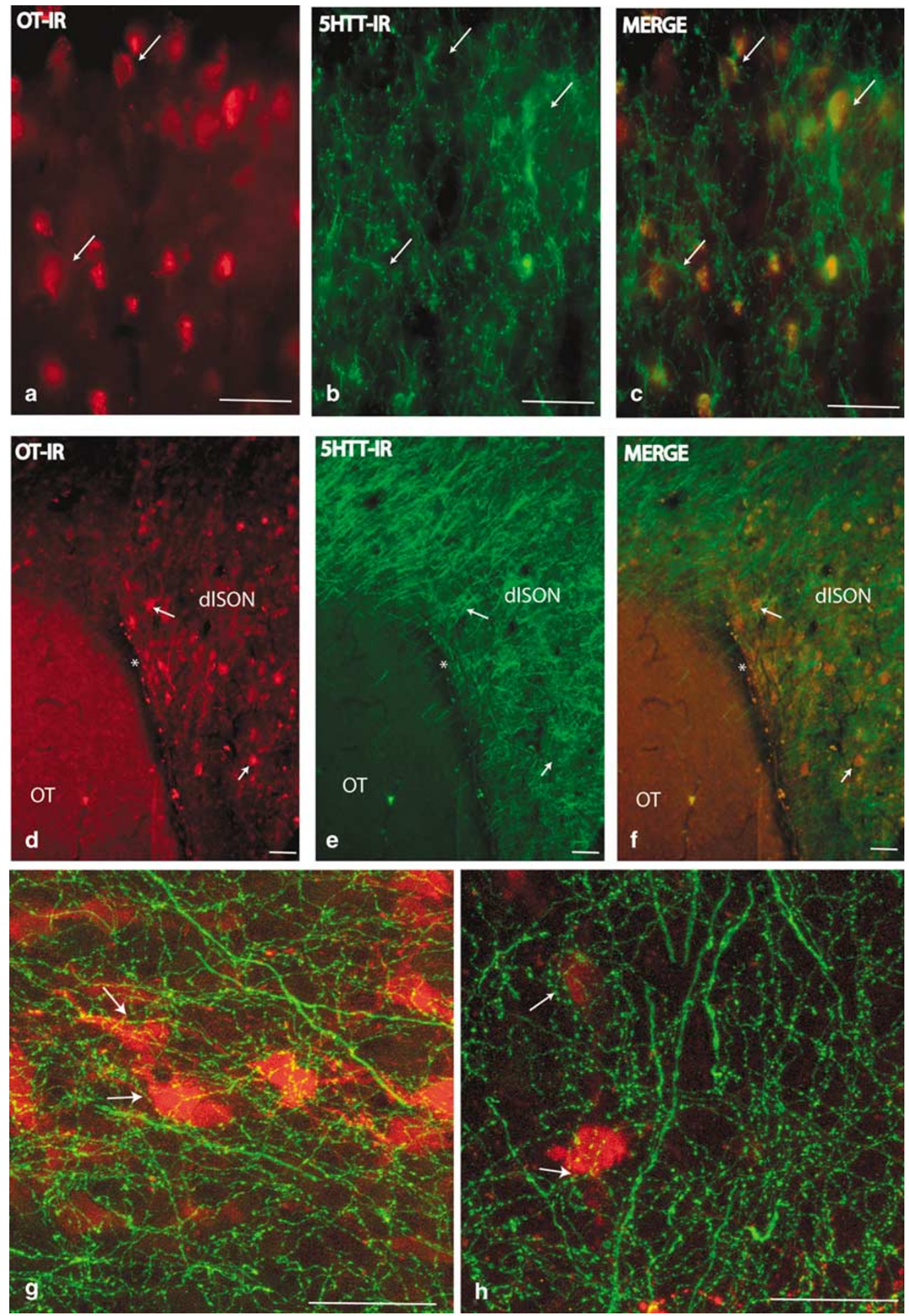

Figure 7 Double immunofluorescent labeling. (a-c) Photomicrograph of region in the PaD, labeled for OT-IR (a, red) and 5-HTT-IR (b, green). Merged image (c) shows OT-labeled cell bodies (red, arrows) embedded in fine meshwork of 5-HTT-labeled fibers (green). Bar $=50 \mu \mathrm{m}$. ( $\mathrm{d}-\mathrm{f}) \mathrm{Macroscopic}$ image of the capsular dISON as it abuts the optic tract. It contains OT-IR cell clusters (a, red), which are overlapped by 5-HTT-labeled fibers (b, green; $c$, merged image). Bar $=100 \mu \mathrm{m}$. (g, h) High power confocal images in the PaD (g), and capsular dISON (h) illustrating the close apposition of 5-HTT-labeled fibers to OT-IR cells (arrows). Bar $=50 \mu \mathrm{m}$.

release. While serotonin administration leads to acute changes in OT release and cell activation (Vacher et al, 2002; Fraga et al, 2005; Jensen et al, 1999; Van de Kar et al,
2001), it also results in upregulation of OT mRNA suggesting a delayed but perhaps prolonged effect on basal OT levels (Jorgensen et al, 2003a). 
Besides a possible involvement in the amelioration of mood symptoms seen in patients treated with SSRIs, available evidence suggests that serotonin enhancement of OT would play a role in the improvement of sexual functioning seen in recovering depression. In rodents, OT is a potent inducer of penile erection when injected into the lateral ventricle or PVN, a phenomenon that is blocked by the administration of OT antagonists (Arletti et al, 1985). OT facilitates sexual behavior in male and female rats, enhancing receptivity and copulatory performance (Arletti and Bertolini, 1985; Caldwell et al, 1986). Projections from OT cells in the PVN to sacral parasympathetic neurons involved in penile erection (Andersson and Wagner, 1995; Tang et al, 1998; Veronneau-Longueville et al, 1999) provide anatomic substantiation for OT's role in sexual behavior. The sexual dysfunction associated with SSRIs is significant, however (Fava and Rankin, 2002; Rosen et al, 1999), and multiple mechanisms for this have been proposed (see review by Rosen et al, (1999)). It is possible that SSRIstimulated OT expression may also drive prolactin release in some individuals, a phenomenon that is associated with sexual dysfunction (see review by Emiliano and Fudge (2004)).

The present results provide anatomic support for the idea that serotonin mediates OT responses in higher primates, which in turn may play a role in symptom relief. Future studies aimed at detailing the input/output pathways of this system, serotonin receptor profiles associated with the OT-containing cells, and the ability of SSRIs to increase OT mRNA and circulating/central OT levels will help test these ideas in primate models.

\section{ACKNOWLEDGEMENTS}

This work was supported in part by funds contributed by CARES, Rochester, NY. We wish to acknowledge the assistance of Howard O'Rourke in manuscript preparation.

\section{REFERENCES}

Altemus M, Deuster PA, Galliven E, Carter CS, Gold PW (1995). Suppression of hypothalmic-pituitary-adrenal axis responses to stress in lactating women. J Clin Endocrinol Metab 80: 2954-2959.

Amico JA, Mantella RC, Vollmer RR, Li X (2004). Anxiety and stress responses in female oxytocin deficient mice. J Neuroendocrinol 16: 319-324.

Andersson KE, Wagner G (1995). Physiology of penile erection. Physiol Rev 75: 191-236.

Arango V, Underwood MD, Boldrini M, Tamir H, Kassir SA, Hsiung $S$ et al (2001). Serotonin 1A receptors, serotonin transporter binding and serotonin transporter mRNA expression in the brainstem of depressed suicide victims. Neuropsychopharmacology 25: 892-903.

Arletti R, Bazzani C, Castelli M, Bertolini A (1985). Oxytocin improves male copulatory performance in rats. Horm Behav 19: 14-20.

Arletti R, Bertolini A (1985). Oxytocin stimulates lordosis behavior in female rats. Neuropeptides 6: 247-253.

Azmitia EC, Gannon PJ (1986). The primate serotonergic system: a review of human and animal studies and a report on Macaca fascicularis. Advan Neurol 43: 407-468.

Bagdy G (1996). Role of the hypothalamic paraventricular nucleus in 5-HT1A, 5-HT2A and 5-HT2C receptor-mediated oxytocin, prolactin and $\mathrm{ACTH} /$ corticosterone responses. Behav Brain Res 73: 277-280.

Bale TL, Davis AM, Auger AP, Dorsa DM, McCarthy MM (2001). CNS region-specific oxytocin receptor expression: importance in regulation of anxiety and sex behavior. J Neurosci 21: 2546-2552.

Blakely RD, De Felice LJ, Hartzell HC (1994). Molecular physiology of norepinephrine and serotonin transporters. J Exp Biol 196: 263-281.

Bodnar I, Banky ZS, Toth BE, Nagy GM, Halasz B (2002). Brain structures mediating the suckling stimulus-induced release of prolactin. J Neuroendocrinol 14: 384-396.

Buijs RM, Van Heerikhuize JJ (1982). Vasopressin and oxytocin release in the brain - a synaptic event. Brain Res 252: 71-76.

Caffe AR, Van Ryen PC, Van der Woude TP, Van Leeuwen FW (1989). Vasopressin and oxytocin systems in the brain and upper spinal cord of Macaca fascicularis. J Comp Neurol 287: 302-325.

Caldwell JD, Prange Jr AJ, Pedersen CA (1986). Oxytocin facilitates the sexual receptivity of estrogen-treated female rats. Neuropeptides 7: 175-189.

Carter CS, Altemus M (1997). Integrative functions of lactational hormones in social behavior and stress management. Ann NY Acad Sci 807: 164-174.

Castren E (2005). Is mood chemistry? Nat Rev Neurosci 6: 241-246.

Chiodera P, Coiro V (1987). Oxytocin reduces metyraponeinduced ACTH secretion in human subjects. Brain Res 420: $178-181$.

Christ JF (1969). Derivation and boundaries of the hypothalamus, with atlas of hypothalamic grisea. In: Haymaker W, Nauta WJH (eds). The Hypothalamus. Charles C. Thomas: Springfield, IL. pp 13-60.

Coccaro EF, Kavoussi RJ, Trestman RL, Gabriel SM, Cooper TB, Siever LJ (1997). Serotonin function in human subjects: intercorrelations among central 5-HT indices and aggressiveness. Psychiatry Res 73: 1-14.

Coiro V, Passeri M, Davoli C, Bachhi-Modena A, Bianconi L, Volpi $\mathrm{R}$ et al (1988). Oxytocin reduces exercise-induced ACTH and cortisol rise in man. Acta Endocrinol 119: 405-412.

De Wied D (1984). Neurohypophyseal hormone influences on learning and memory processes. In: Lynch G, McGaugh JL, Weinberger NM (eds). Neurobiology of Learning and Memory. Guilford Press: New York. pp 289-321.

Dierickx K, Vandesande F (1977). Immunocytochemical localization of the vasopressinergic and the oxytocinergic neurons in the human hypothalamus. Cell Tissue Res 184: 15-27.

Dubois-Dauphin M, Armstrong WE, Tribollet E, Dreifuss JJ (1985a). Somatosensory systems and the milk-ejection reflex in the rat. I. Lesions of the mesencephalic lateral tegmentum disrupt the reflex and damage mesencephalic somatosensory connections. Neuroscience 15: 1111-1129.

Dubois-Dauphin M, Armstrong WE, Tribollet E, Dreifuss JJ (1985b). Somatosensory systems and the milk-ejection reflex in the rat. II. The effects of lesions in the ventroposterior thalamic complex, dorsal columns and lateral cervical nucleus-dorsolateral funiculus. Neuroscience 15: 1131-1140.

Ebner K, Bosch OJ, Kromer SA, Singewald N, Neumann ID (2005). Release of oxytocin in the rat central amygdala modulates stresscoping behavior and the release of excitatory amino acids. Neuropsychopharmacology 30: 223-230.

Emiliano AB, Fudge JL (2004). From galactorrhea to osteopenia: rethinking serotonin-prolactin interactions. Neuropsychopharmacology 29: 833-846.

Fava M, Rankin M (2002). Sexual functioning and SSRIs. J Clin Psychiatr 63(Suppl 5): 13-16; discussion 23-15.

Febo M, Ferris CF (2005). Functional magnetic resonance imaging shows oxytocin activates brain regions associated with motherpup bonding during suckling. J Neurosci 25: 11637-11644.

Ferris CF, Kulkarni P, Sullivan Jr JM, Harder JA, Messenger TL, Febo M (2005). Pup suckling is more rewarding than cocaine: 
evidence from functional magnetic resonance imaging and three-dimensional computational analysis. $J$ Neurosci 25: 149-156.

Fliers E, Guldenaar SE, van de Wal N, Swaab DF (1986). Extrahypothalamic vasopressin and oxytocin in the human brain; presence of vasopressin cells in the bed nucleus of the stria terminalis. Brain Res 375: 363-367.

Fliers E, Swaab DF, Pool CW, Verwer RW (1985). The vasopressin and oxytocin neurons in the human supraoptic and paraventricular nucleus; changes with aging and in senile dementia. Brain Res 342: 45-53.

Fodor M, Gorcs TJ, Palkovits M (1992). Immunohistochemical study on the distribution of neuropeptides with the pontine tegmentum-particularly the parabrachial nuclei and the locus coeruleus of the human brain. Neuroscience 46: 891-908.

Fraga IC, Fregoneze JB, Carvalho FLQ, Dantas KB, Azevedo CS, Pinho $\mathrm{CB}$ et al (2005). Acute fluoxetine administration differently affects brain c-fos expression in fasted and refed rats. Neuroscience 134: 327-334.

Fukuoka T, Negoro H, Honda K, Higuchi T, Nishida E (1984). Spinal pathway of the milk-ejection reflex in the rat. Biol Reproduct 30: 74-81.

Heinrichs M, Meinlschmidt G, Neumann I, Wagner S, Kirschbaum C, Ehlert U et al (2001). Effects of suckling on hypothalamicpituitary-adrenal axis responses to psychosocial stress in postpartum lactating women. J Clin Endocrinol Metabol 86: 4798-4804.

Holsboer F, Lauer CJ, Schreiber W, Krieg JC (1995). Altered hypothalamic-pituitary-adrenocortical regulation in healthy subjects at high familial risk for affective disorders. Neuroendocrinology 62: 340-347.

Insel TR (1992). Oxytocin - a neuropeptide for affiliation: evidence from behavioral, receptor autoradiographic, and comparative studies. Psychoneuroendocrinology 17: 3-35.

Insel TR (2003). Is social attachment an addictive disorder? Physiol Behav 79: 351-357.

Javed A, Kamradt MC, Van de Kar LD, Gray TS (1999). D-Fenfluramine induces serotonin-mediated Fos expression in corticotropin-releasing factor and oxytocin neurons of the hypothalamus, and serotonin-independent Fos expression in enkephalin and neurotensin neurons of the amygdala. Neuroscience 90: 851-858.

Jensen JB, Jessop DS, Harbuz MS, Mork A, Sanchez C, Mikkelsen JD (1999). Acute and long-term treatments with the selective serotonin reuptake inhibitor citalopram modulate the HPA axis activity at different levels in male rats. J Neuroendocrinol 11: $465-471$.

Jorgensen H, Kjaer A, Knigge U, Moller M, Warberg J (2003a). Serotonin stimulates hypothalamic mRNA expression and local release of neurohypophysial peptides. J Neuroendocrinol 15: 564-571.

Jorgensen H, Riis M, Knigge U, Kjaer A, Warberg J (2003b). Serotonin receptors involved in vasopressin and oxytocin secretion. J Neuroendocrinol 15: 242-249.

Kawata M, Sano Y (1982). Immunohistochemical identification of the oxytocin and vasopressin neurons in the hypothalamus of the monkey (Macaca fuscata). Anat Embryol 165: 151-167.

Kent DL, Sladek Jr J (1978). Histochemical, pharmacological and microspectrofluorometric analysis of new sites of serotonin localization in the rat hypothalamus. J Comp Anat 180: 221-236.

Kirsch P, Esslinger C, Chen Q, Mier D, Lis S, Siddhanti S et al (2005). Oxytocin modulates neural circuitry for social cognition and fear in humans. J Neurosci 25: 11489-11493.

Koutcherov Y, Mai JK, Ashwell KW, Paxinos G (2000). Organization of the human paraventricular hypothalamic nucleus. J Comparat Neurol 423: 299-318.

Kugaya A, Sanacora G, Staley JK, Malison RT, Bozkurt A, Khan S et al (2004). Brain serotonin transporter availability predicts treatment response to selective serotonin reuptake inhibitors. Biol Psychiatry 56: 497-502.

Lee R, Garcia F, van de Kar LD, Hauger RD, Coccaro EF (2003). Plasma oxytocin in response to pharmaco-challenge to D-fenfluramine and placebo in healthy men. Psychiatry Res 118: $129-136$.

Legros JJ, Chiodera P, Demey-Ponsart E (1982). Inhibitory influence of exogenous oxytocin on adrenocorticotropin secretion in normal human subjects. J Clin Endocrinol Metabol 55: 1035-1039.

Lightman SL, Harbuz MS, Knight RA, Chowdrey HS (1993). CRF mRNA in normal and stress conditions. Annal NY Acad Sci 697: 28-38.

LuQui IJ, Fox CL (1976). The supraoptic nucleus and the supraopticohypophysial tract in the monkey (Macaca mulatta). J Comp Neurol 168: 7-39.

Mantella RC, Vollmer RR, Li X, Amico JA (2003). Female oxytocindeficient mice display enhanced anxiety-related behavior. Endocrinology 144: 2291-2296.

Moos F, Richard P (1983). Serotonergic control of oxytocin release during suckling in the rat: opposite effects in conscious and anesthetized rats. Neuroendocrinology 36: 300-306.

Muhlethaler M, Raggenbass M, Kreifuss JJ (1985). Oxytocin and vasopressin. In: Rogawski MA, Barker JL (eds). Neurotransmitter Actions in the Vertebrate Nervous System. Plenum Press: New York. pp 439-458.

Naranjo CA, Tremblay LK, Busto UE (2001). The role of the brain reward system in depression. Prog Neuro-Psychopharmacol Biol Psychiatry 25: 781-823.

Nauta WJH, Haymaker W (1969). Hypothalamic nuclei and fiber connections. In: Haymaker W, Anderson ER, Nauta WJH (eds). The Hypothalamus. Charles C. Thomas: Springfield, IL. pp 136-209.

Nelson JC, Charney DS (1981). The symptoms of major depressive illness. Am J Psychiatry 138: 1-13.

Neumann ID, Torner L, Wigger A (2000). Brain oxytocin: differential inhibition of neuroendocrine stress responses and anxiety-related behaviour in virgin, pregnant and lactating rats. Neuroscience 95: 567-575.

Nobin A, Bjorklund A (1973). Topography of the monoamine system in the human brain as revealed in fetuses. Acta Physiol Scand Suppl 388: 1-40.

Rosen RC, Lane RM, Menza M (1999). Effects of SSRIs on sexual function: a critical review. J Clin Psychopharmacol 19: 67-85.

Saper CB (1990). Hypothalamus. In: Paxinos G (ed). The Human Nervous System. Academic Press Inc: San Diego, CA. pp 389-413.

Sawchenko PE, Swanson LW, Steinbusch HW, Vernhofstad AJ (1983). The distribution and cells of origin of serotonergic inputs to the paraventricular and supraoptic nuclei of the rat. Brain Res 227: $355-360$

Saydoff JA, Rittenhouse PA, van de Kar LD, Brownfield MS (1991). Enhanced serotonergic transmission stimulates oxytocin secretion in conscious male rats. J Pharmacol Exp Therapeut 257: 95-99.

Scharrer E, Scharrer B (1940). Secretor cells within the hypothalamus. Proc Assoc Res Nerv Ment Disord 20: 170-194.

Schofield SP, Everitt BJ (1981). The organization of indoleamine neurons in the brain of the rhesus monkey (Macaca mulatta). J Comparat Neurol 197: 369-383.

Shapiro LE, Insel TR (1992). Oxytocin receptor distribution reflects social organization in monogamous and polygamous voles. Annal NY Acad Sci 652: 448-451.

Siever LJ, Murphy DL, Slater S, de la Vega E, Lipper S (1984). Plasma prolactin changes following fenfluramine in depressed patients compared to controls: an evaluation of central serotonergic responsivity in depression. Life Sci 34: 1029-1039. 
Sofroniew MV (1980). Projections from vasopressin, oxytocin, and neurophysin neurons to neural targets in the rat and human. J Histochem Cytochem 28: 475-478.

Sofroniew MV, Weindl A, Schrell U, Wetzstein R (1981). Immunohistochemistry of vasopressin, oxytocin and neurophysin in the hypothalamus and extrahypothalamic regions of the human and primate brain. Acta Histochem-Suppl 24: 79-95.

Steinbusch HW, Nieuwenhuys R (1981). Localization of serotoninlike immunoreactivity in the central nervous system and pituitary of the rat, with special references to the innervation of the hypothalamus. Advan Exp Med Biol 133: 7-35.

Swaab DF, Fliers E, Hoogendijk WJ, Veltman DJ, Zhou JN (2000). Interaction of prefrontal cortical and hypothalamic systems in the pathogenesis of depression. Prog Brain Res 126: 369-396.

Swanson LW, Kuypers HG (1980). The paraventricular nucleus of the hypothalamus: cytoarchitectonic subdivisions and organization of projections to the pituitary, dorsal vagal complex, and spinal cord as demonstrated by retrograde fluorescence doublelabeling methods. J Comp Neurol 194: 555-570.

Tang Y, Rampin O, Calas A, Facchinetti P, Giuliano F (1998). Oxytocinergic and serotonergic innervation of identified lumbosacral nuclei controlling penile erection in the male rat. Neuroscience 82: 241-254.

Tasker JG, Theodosis DT, Poulain DA (1986). Afferent projections from the mammary glands to the spinal cord in the lactating rat - I. A neuroanatomical study using the transganglionic transport of horseradish peroxidase-wheatgerm agglutinin. Neuroscience 19: 495-509.

Tribollet E, Dreifuss JJ (1981). Localization of neurones projecting to the hypothalamic paraventricular nucleus area of the rat: a horseradish peroxidase study. Neuroscience 6: 1315-1328.
Uvnas-Moberg K, Bjokstrand E, Hillegaart V, Ahlenius S (1999). Oxytocin as a possible mediator of SSRI-induced antidepressant effects. Psychopharmacology 142: 95-101.

Vacher CM, Fretier P, Creminon C, Calas A, Hardin-Pouzet H (2002). Activation by serotonin and noradrenaline of vasopressin and oxytocin expression in the mouse paraventricular and supraoptic nuclei. J Neurosci 22: 1513-1522.

Van de Kar LD, Javed A, Zhang Y, Serres F, Raap DK, Gray TS (2001). 5-HT2A receptors stimulate ACTH, corticosterone, oxytocin, renin, and prolactin release and activate hypothalamic CRF and oxytocin-expressing cells. J Neurosci 21: 3572-3579.

Van de Kar LD, Rittenhouse PA, Li Q, Levy AD, Brownfield MS (1995). Hypothalamic paraventricular, but not supraoptic neurons, mediate the serotonergic stimulation of oxytocin secretion. Brain Res Bull 36: 45-50.

Vandesande F, Dierickx K (1975). Identification of the vasopressin producing and of the oxytocin producing neurons in the hypothalamic magnocellular neurosecretroy system of the rat. Cell Tissue Res 164: 153-162.

Veronneau-Longueville F, Rampin O, Freund-Mercier MJ, Tang Y, Calas A, Marson L et al (1999). Oxytocinergic innervation of autonomic nuclei controlling penile erection in the rat. Neuroscience 93: 1437-1447.

Windle RJ, Kershaw YM, Shanks N, Wood SA, Lightman SL, Ingram CD (2004). Oxytocin attenuates stress-induced c-fos mRNA expression in specific forebrain regions associated with modulation of hypothalamo-pituitary-adrenal activity. J Neurosci 24: 2974-2982.

Windle RJ, Shanks N, Lightman SL, Ingram CD (1997). Central oxytocin administration reduces stress-induced corticosterone release and anxiety behavior in rats. Endocrinology 138: 2829-2834. 